\title{
A Novel Framework to Consider Endogenous Hormonal Control of Apple Tree Flowering
}

\author{
Brian P. Pellerin ${ }^{1}$ \\ Nova Scotia Fruit Growers' Association, 32 Main Street, Kentville, Nova \\ Scotia B4N 1J5, Canada
}

\section{Deborah Buszard}

College of Sustainability, Dalhousie University, 6050 University Avenue, Halifax, Nova Scotia B3H 1 W5 Canada

\author{
Alex Georgallas \\ Department of Engineering, Nova Scotia Agricultural College, P.O. Box 550, \\ Truro, Nova Scotia B2N 5 E3 Canada
}

\section{Richard J. Nowakowski \\ Department of Mathematics and Statistics, Dalhousie University, Halifax, Nova Scotia B3H $3 J 5$ Canada}

Additional index words. Malus sylvestris Borkh., gibberellic acid, jasmonic acid, 9,10-ketoloctadecadienoic acid, mathematical modeling, maximum annual percent bloom

\begin{abstract}
Inhibition of flower initiation by nearby developing fruits is one of the main causes of biennial bearing in apple trees. This localized inhibition may depend on a critical ratio of inhibitor and promoter hormones that inhibits flowering of apical meristems. A model is proposed to explain this phenomenon. In the model, it is assumed that seeds and leaves act as point sources and export inhibiting and promoting hormones to apical meristems. The model assumes critical ratios of promoting and inhibiting hormones determine whether an apical meristem flowers or not and this may be a cause of biennial bearing. Thus, the spatial arrangement of shoot apical meristems on a limb is perhaps critical in determining whether meristems initiate flower clusters. This article presents a novel framework to view the hormone hypotheses of biennial bearing in apple trees and how management strategies such as flower removal could be used to achieve regular numbers of flower clusters over consecutive years.
\end{abstract}

Profitable apple production requires regular yields of marketable fruits. The challenge is that many commercially important cultivars are biennial, producing excessive numbers of flower clusters and fruits in one year, which suppress flower initiation for the next year. This leads to oscillation in crops between many small, poor-quality fruits in one year and a few large fruits or no fruits at all in alternate years (Stover et al., 2001). Rootstock and environmental factors such as drought, spring frost, diseases, light interception, and canopy architecture manipulation can also impact the bearing pattern of apple trees (Davis, 2002; Fulford, 1965; Willaume et al., 2004).

High crop yields inhibit flower initiation. Chan and Cain (1967) showed the effects of

\footnotetext{
Received for publication 18 Nov. 2011. Accepted for publication 16 Mar. 2012.

Funding was provided by the MITACS Accelerate program.

We acknowledge Dalhousie University, the Nova Scotia Agricultural College, Parks Canada, and the Nova Scotia Fruit Growers' Association for supporting this project.

${ }^{1}$ To whom reprint requests should be addressed; e-mail pellerinb@nsac.ca.
}

seeded and seedless fruit on return bloom and concluded that hormones exported from the seeds inhibit floral initiation. They showed that only the pollinated side of the parthenocarpic apple cultivar Spencer Seedless had no return bloom, demonstrating floral inhibition to be a localized effect. Subsequent work has tried to identify the hormones involved.

The distance between flower clusters in one year has long been known to influence the development of floral buds for the next year (Fulford, 1966). 'Wealthy', a strongly biennial cultivar, requires a minimum distance of 15 to $25 \mathrm{~cm}$ between individual flower clusters, approximately equivalent to 40 flower clusters $/ \mathrm{m}^{3}$ of canopy volume, to maintain regular yields (Bobb and Blake, 1938). More recent work on 'Honeycrisp', a strongly biennial cultivar, demonstrated that pruning short $(1-10 \mathrm{~cm})$ branches known as spurs to reduce flower cluster number to between 40 and $60 / \mathrm{m}^{3}$ of canopy volume is necessary to control biennial bearing (Nichols et al., 2011). These studies and others suggest that biennial bearing may be a result of carbon limitation and/or hormonal inhibition of floral initiation by nearby seeds as reported by Dennis (2000) and Tromp (2000). However, none of these studies conclusively settled the question.
The balance of hormone concentrations has been hypothesized to control floral initiation (Callejas and Bangerth, 1997; Hoad, 1984; Luckwill, 1970). Before 2000, there had been many conflicting reports on the effects of applying exogenous hormones on concentrations of endogenous hormones such as auxins, gibberellins, cytokinins, and abscisic acid (Grochowska, 1968; Ramírez and Hoad, 1981). These are well reviewed by Dennis and Neilsen (1999).

In more recent years, endogenous gibberellins (possibly $\mathrm{GA}_{1}, \mathrm{GA}_{4}$, and iso- $\mathrm{GA}_{7}$ ) produced by seeds have been shown to inhibit floral initiation in 'Golden Delicious' (Ramírez et al., 2004a, 2004b). This was confirmed with heavily cropping 'Fuji' trees having higher concentrations of endogenous $\mathrm{GA}_{1}$ and $\mathrm{GA}_{4}$ in apical buds at the time of floral initiation than was found on blossom-thinned trees (Kittikorn et al., 2010). Other endogenous hormones [9,10-ketol-octadecadienoic acid (KODA) and jasmonic acid (JA)] have been found at high concentrations in apple trees when GAs are low (blossom-thinned trees) and at low concentrations when GAs are high (heavily bearing trees). KODA and JA are associated with flower induction in other plants and may promote floral initiation in apple (Kittikorn et al., 2010, 2011; Kong et al., 2005; Suzuki et al., 2003; Yokoyama et al., 2000, 2005)

Thus, although more than 70 years have passed since Bobb and Blake identified the effect of a heavy crop on return bloom, the underlying mechanisms remain unclear and hypotheses remain unconfirmed. Mathematical modeling may help researchers better understand the phenomenon and clarify the mechanisms involved. This article models the hypothesis originally developed by Hoad (1984) that a balance of hormones controls flower initiation in apple trees and predicts the effect of flower thinning on percent bloom in the next year.

\section{Theory and Model}

According to the hormone balance hypothesis, seeds export inhibitor hormones and leaves export promoter hormones (Callejas and Bangerth, 1997). We assume for the purpose of modeling that shoot apical meristems (SAMs) flower unless the ratio of inhibitor to promoter hormones is greater than a critical value.

The model first creates the canopy structure of a mature tree and randomly assigns flower clusters and vegetative growth to the SAMs. The ratio of inhibitor to promoter hormones coming from seeds and leaves is estimated at each SAM.

The model generates hypothetical trees with 1000 SAMs; it does not include any function of aging or growth. Using R, a standard programming language for computation and graphics (R Development Core Team, 2011), trees were generated with the "rtree" function within the Analyses of Phylogenetics and Evolution ("ape") software package (see Appendix A; Paradis et al., 2004). 
This function assembles trees from branch lengths as shown in Figure 1. Branch lengths are selected from a random distribution between 0 and $20 \mathrm{~cm}$ using the standard "sample" function (see "br" in Appendix A). This distribution is based on the distribution of branch lengths measured for 138 'Honeycrisp' branches on mature (7- to 10-year-old) trees on MM.106 and M.26 rootstocks in the Annapolis Valley, Nova Scotia, Canada, from 2009 to 2011 (personal observation). Further details about "rtree" and how it builds trees from branch lengths can be found by entering "?rtree" in R after installing the "ape" package. The R package "ape" and similar packages of R ("ade4," "adephylo," and "seqinr") are standard tools for analyzing phylogenetic trees (Freckleton and Jetz, 2009). For the agricultural modeler, the functions offer powerful measurement tools to simulate and analyze trees and other branching systems.

The hormonal control of the biennialbearing hypothesis assumes seeds and leaves produce hormones (Dennis and Neilsen, 1999). The point source equation, common to physics, is a useful tool in which signal intensity at distance $r$ can be demonstrated to be $\mathrm{I}=\alpha / \mathrm{r}^{(\mathrm{D}-1)}$ where $\alpha(0 \leq \alpha \leq 1)$ is the signal strength at the point source and D is the fractal dimension (Griffith, 2004).

Fractal dimension is the amount of space an object completely fills (Mandelbrot, 1967; Vicsek, 2001). A solid cube has a fractal dimension of three, whereas a straight line has a fractal dimension of one. Imagine a cube of wood that will be carved into the shape of a tree. While it is still uncut, the fractal dimension is three but as the carving appears, the fractal dimension decreases. Similarly, the fractal dimension of a real apple tree is somewhere between one (a straight line) and three (a solid cube). The more the tree fills the cube, the greater the fractal dimension. Trees have been mathematically modeled as fractals (Holiday and Samal, 1995; Prusinkiewicz and Lindenmayer, 1990; Samal et al., 2002).

Fractals have the property that their length is indeterminate. For instance, measuring a coastline with a $1-\mathrm{km}$ scale will have a shorter length than measuring with a $1-\mathrm{m}$ scale and a still shorter length than measuring with a $1-\mathrm{cm}$ scale. This property, known as the Richardson effect, is used to estimate the fractal dimension by repeatedly measuring its length $(\mathrm{L})$ with different size measuring scales (S) and solving for $\mathrm{D}$ in the regression equation $\log [\mathrm{L}]=$ (1-D) $\log [\mathrm{S}]+\mathrm{b}$ (Mandelbrot, 1967; Zhang et al., 2007). In this model, the calculation

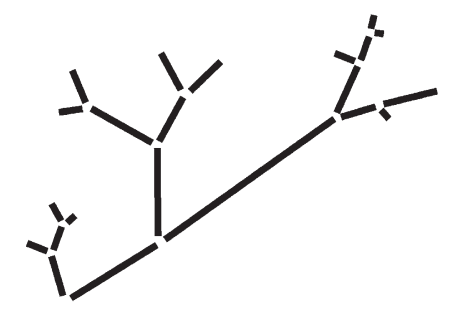

Fig. 1. A simulated branch assembled from 22 branch lengths. was done with two scale sizes ( $1 \mathrm{~cm}$ and $60 \%$ of the maximum distance between tips) for the generated trees and used in the point source equation (Appendix A).

The model measures the branch distances between point sources (branch tips). In terms of $\mathrm{R}$ code, the function used is "cophenetic" in the $\mathrm{R}$ stats package. The cophenetic distance is the branch distance between every SAM (R Development Core Team, 2011). Using the point source equation, these distances are converted to concentrations of hormone from seeds and leaves (see "chs" and "chl" in Appendix A). The concentration of hormones as they spread from a point source through the tree would be distributed as shown in Figure 2 where $\alpha=1$ and $D=1.5$.

In the model, seeds and leaves export equal quantities of hormone (between zero and one) or one exports $1 / 10$ th (between zero and 0.1 ) of the quantity of the other. These regimes were selected to represent possible real-life scenarios. In reality, hormone levels are not known. Floral inhibition is simulated by comparing the hypothetical hormone ratio at each SAM to a critical value beyond which flowering is inhibited (see "crit" in Appendix A).

The model also simulates thinning, the removal of fruiting SAMs before they export inhibiting hormones. Thinning removes $t$ percent of the fruiting SAMs. In the model, thinning is done between $0 \%$ and $100 \%$ at $5 \%$ intervals in the third year (the on-year) and replicated 1000 times (see " $t$ " in Appendix A). Distances between individual flowering/ fruiting SAMs were calculated for each $t$ percent of thinning and were an average of $21.5 \mathrm{~cm}$ for all $t$ percent thinning less than $100 \%$.

\section{Results}

The fractal dimension of the model tree canopy ranged between 1.69 and 1.85 with a mean of 1.77 and a SD of 0.02 . The model simulated the percentage of fruiting SAMs in the first year and the next year against the critical ratio of inhibitor to promoter hormones (Fig. 3) and against thinning in the onyear using critical ratios of 1:1, 1:2, 1:4, 1:8, and 1:16 (Fig. 4). Changing the relative amounts of hormones exported by seeds and leaves from $1: 10,1: 1$, and 10:1 shifted the plot by a magnitude of 10 each time (Fig. 3). The corresponding maximum annual values for the plots in Figure 4 are $50 \%, 41 \%, 30 \%$, $22 \%$, and $16 \%$ fruiting SAMs. The model simulated the percentage of fruiting SAMs in the first year and the next year against the critical ratio of inhibitor to promoter hormones (Fig. 3) and against thinning in the onyear using critical ratios of 1:1, 1:2, 1:4, 1:8, and 1:16 (Fig. 4). Changing the relative amounts of hormones exported by seeds and leaves from 1:10, 1:1, and 10:1 shifted the plot by a magnitude of 10 each time (Fig. 3). The corresponding maximum annual values for the plots in Figure 4 are 50\%, 41\%, 30\%, $22 \%$, and $16 \%$ fruiting meristems.

\section{Discussion}

Many apple cultivars exhibit biennial bearing, which several authors have attributed to relative concentrations of floral inhibiting and promoting hormones (Kittikorn et al., 2010; Luckwill, 1970). This theoretical model represents the hormone ratio hypothesis mathematically with simulated mature trees. In the model, leaves export promoting hormones and

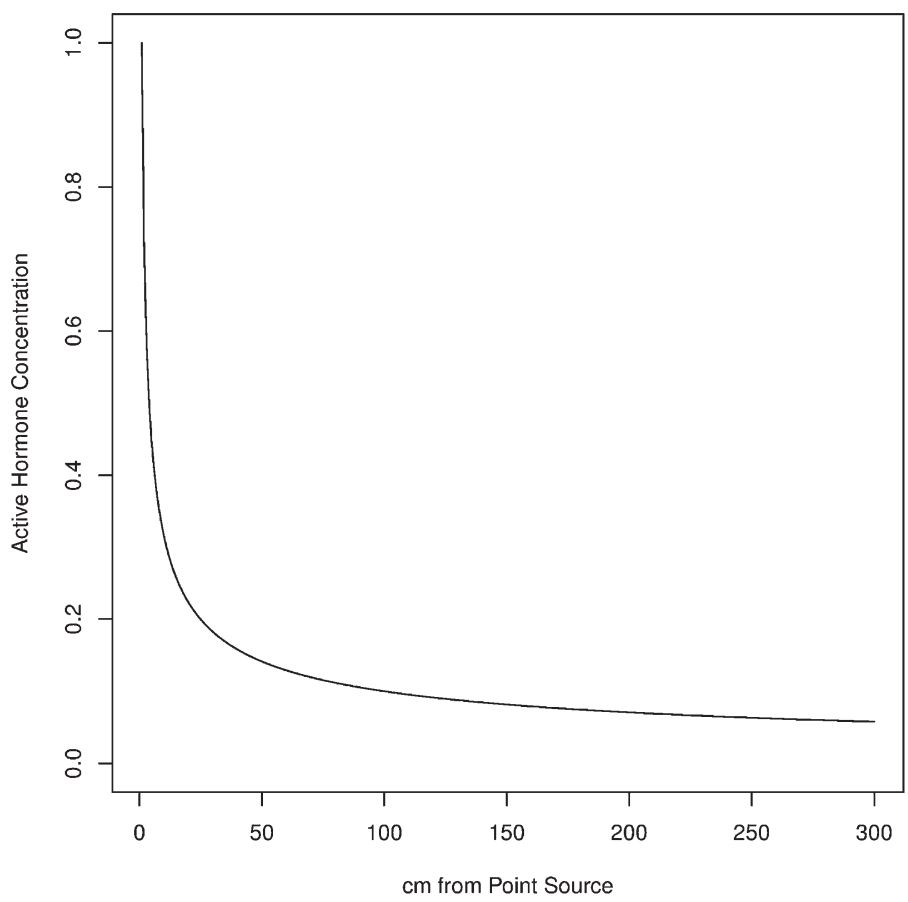

Fig. 2. Estimated hormone concentration along the branch using the point source equation $\mathrm{I}=\alpha / r^{\mathrm{D}-1}$ where $\alpha=1$ is the initial concentration, $r$ is the distance along the limb, and $\mathrm{D}=1.5$ is the fractal dimension. 

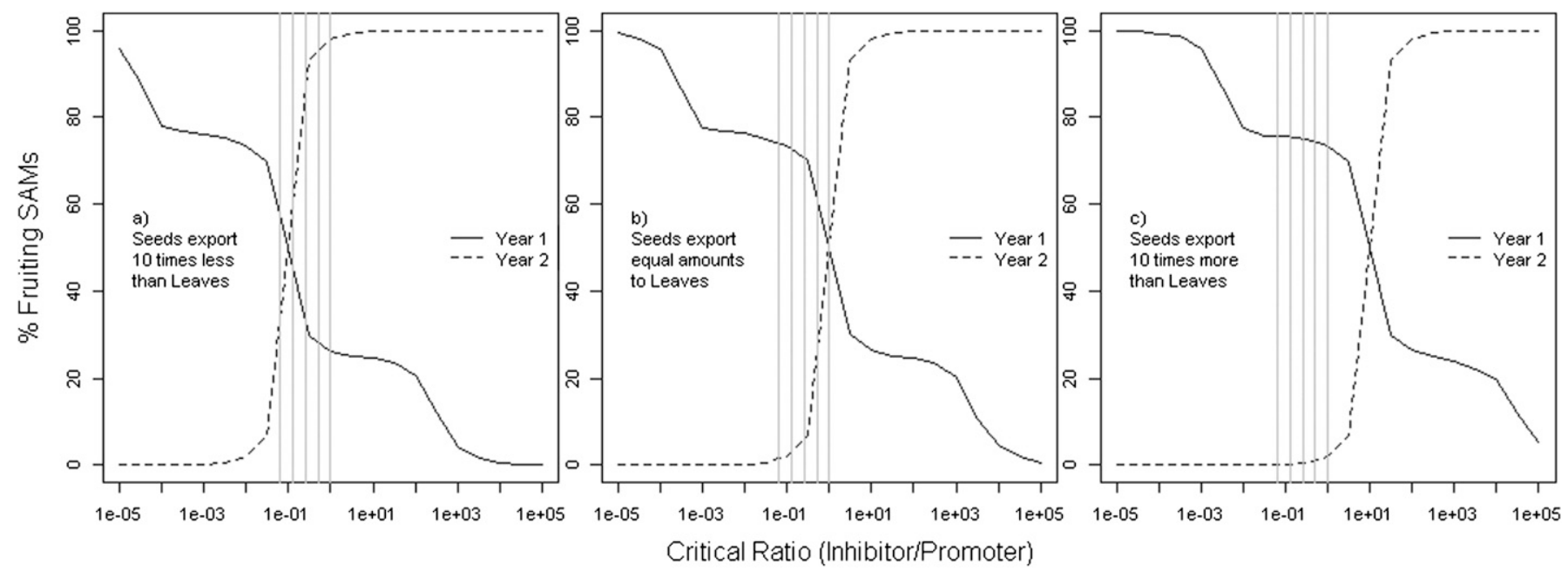

Fig. 3. Percent fruiting SAMs in the first year (solid line) and the next year (dashed line) plotted against the critical ratio of inhibitor to promoter hormones. The relative quantity of hormones exported by seeds and leaves is (A) 10:1, (B) 1:1, and (C) 1:10. Vertical lines indicate critical ratios of 1:1, 1:2, 1:4, 1:8, and 1:16. $\mathrm{SAMs}=$ shoot apical meristems.
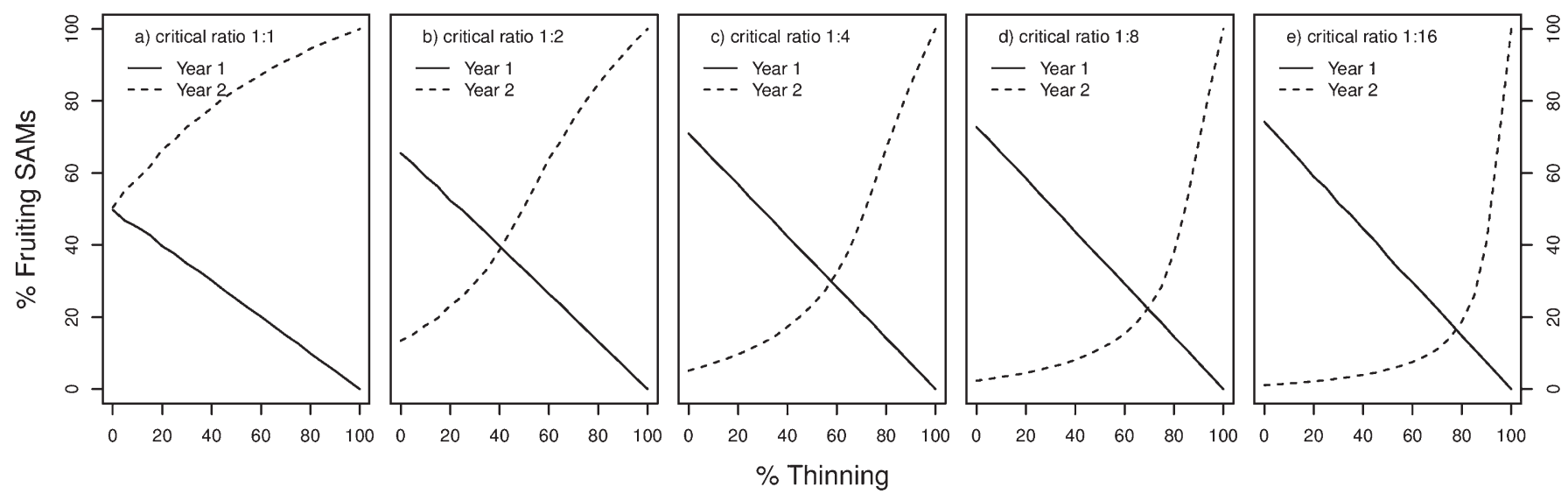

Fig. 4. Percent fruiting SAMs remaining after thinning in the first year (solid line) and the percent fruiting SAMs in the next year (dashed line). Seeds and leaves export equal amounts of hormone and flower inhibition occurs at the critical ratios of (A) 1:1, (B) 1:2, (C) 1:4, (D) 1:8, and (E) 1:16 inhibitor to promoter hormones. SAMs $=$ shoot apical meristems.

seeds export inhibiting hormones. These hormones spread throughout the tree and SAMs receive both inhibiting and promoting hormones in proportions related to their location.

The point source equation is used to represent hormone concentration over distance from its source. This equation supports the concept of distance-dependent floral inhibition as seen from the results of Bobb and Blake (1938). Because floral inhibition has been observed to be a localized effect (Bobb and Blake, 1938; Chan and Cain, 1967), the spatial arrangement of SAMs on a limb is perhaps as critical as the number in determining whether individual SAMs initiate flower clusters.

When a tree is carrying many fruit, the local effect of inhibiting flower development for the next year is so widespread as to cause biennial bearing. If, as Hoad (1984) suggests, flowering is inhibited when the ratio of inhibitor to promoter hormones reaches a critical value, we would expect to find a range of possible critical values that could cause biennial bearing. This appears to be the case using the model, as shown in Figure 3. The plot shifts depending on how much hormone seeds and leaves export. The model indicates a large range of critical ratios could cause biennial bearing (Fig. 3). Critical hormone ratios are known to be involved in switching processes on or off in numerous plant stages such as germination (Kucera et al., 2005), cell growth (Müller and Sheen, 2008), and fruit growth (Cowan et al., 2001).

The aim of thinning apple trees is to control biennial bearing and optimize fruit yields. The model shows a non-linear response to thinning (Fig. 4). This appears to confirm the observations of Bailey (1929) who recorded return bloom of two biennial cultivars in their off-year after removing $50 \%, 75 \%$, and $100 \%$ of the blossoms by hand in the on-year. Only his $100 \%$ thinning treatment consistently gave return bloom. A critical ratio of $1: 16$ inhibitor to promoter hormones gives a similar response in the model (Fig. 4E).

Modeling could help predict the effect of thinning on return bloom and how to achieve relatively equal numbers of flowers from year to year. This is difficult to achieve in reality, particularly on cultivars prone to bienniality. Where reproductive and vegetative point sources export equal amounts of hormone, as shown in Figure 4A, the maximum annual percentages of fruiting SAMs for critical hormone ratios of $1: 1,1: 2,1: 4,1: 8$, and $1: 16$ are $50 \%, 41 \%, 30 \%, 22 \%$, and $16 \%$; the amount of thinning required was $0 \%$, $40 \%, 60 \%, 70 \%$, and $78 \%$, respectively. The five graphs in Figure 4 represent varying levels of bienniality. They show the variety of return bloom responses to a range of thinning regimes. This model outcome is in line with results reported in a recent apple orchard model by Hester and Cacho (2003), which predicts optimal thinning strategies for a 15 -year period.

This model presents a logic framework, which shows how easily biennial bearing can be established. This may be useful to growers, fruit breeders, and others seeking to understand the impact of flower bud proximity and branch architecture on crop yield. Field experiments are needed to validate the model 
and determine its applicability to specific cultivars, management systems, and environments. It could be a powerful tool to manage biennial bearing. We encourage criticism of the model and welcome opportunities to collaborate with other researchers and refine and field test the model for different cultivars and environments.
Appendix A. Essential R code to create the flowering branch model.

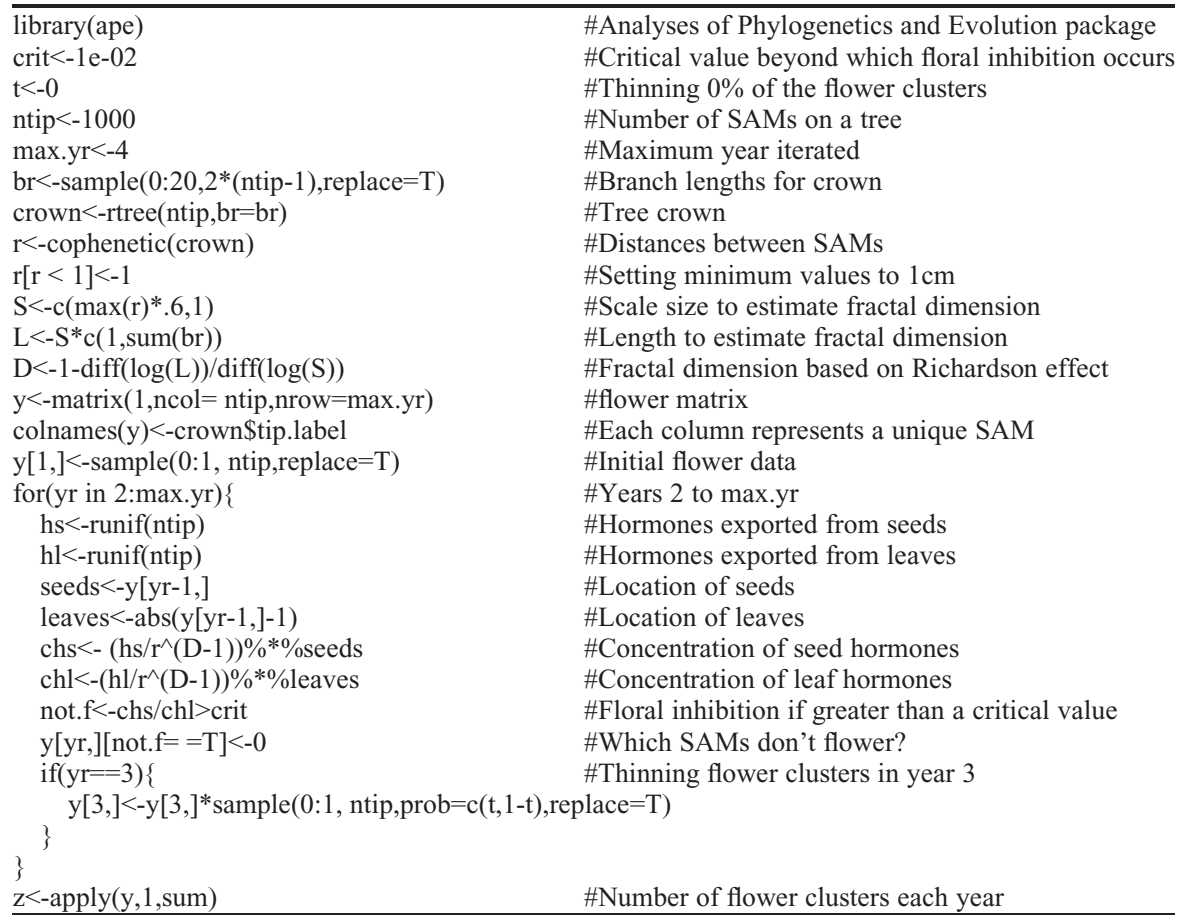

$\mathrm{SAM}=$ shoot apical meristem.

\section{Literature Cited}

Bailey, J.S. 1929. The effect of apple blossom removal on flower bud formation. Proc. Amer. Soc. Hort. Sci. 25:198-201.

Bobb, A.C. and M.A. Blake. 1938. Annual bearing in the Wealthy apple was induced by blossom thinning. Proc. Amer. Soc. Hort. Sci. 36:321-327.

Callejas, R. and F. Bangerth. 1997. Is auxin export of apple fruit an alternative signal for initiation of flower bud induction? Acta Hort. 463: 271-277.

Chan, B.G. and J.C. Cain. 1967. The effect of seed formation on subsequent flowering in apple. Proc. Amer. Soc. Hort. Sci. 91:63-68.

Cowan, A.K., R.F. Cripps, E.W. Richings, and N.J. Taylor. 2001. Fruit size: Towards an understanding of the metabolic control of fruit growth using avocado as a model system. Physiol. Plantar. 111:127-136.

Davis, D.E. 2002. Inhibition of flower bud initiation and development in apple by defoliation, gibberellic acid and crop load manipulation. $\mathrm{PhD}$ thesis, Virginia Polytechnic Institute.

Dennis,, F.G., Jr. 2000. The history of fruit thinning. Plant Growth Regulat. 31:1-16.

Dennis, F.G., Jr. and J.C. Neilsen. 1999. Physiological factors affecting biennial bearing in tree fruit: The role of seeds in apple. HortTechnology 9:317-322.

Freckleton, R.P. and W. Jetz. 2009. Space versus phylogeny: Disentangling phylogenetic and spatial signals in comparative data. Proc. Biol. Sci. 276:21-30.

Fulford, R.M. 1965. Regular and irregular bearing in fruit plants. Ann. Rep. East Malling Res. Stn. 48:71-82.
Fulford, R.M. 1966. The morphogenesis of apple buds. IV. The effect of fruit. Ann. Bot. (Lond.) 30:597-606.

Griffith, W.T. 2004. The physics of everyday phenomena: A conceptual introduction to physics. 4th Ed. McGraw-Hill, New York, NY.

Grochowska, M. 1968. The influence of growth regulators inserted into apple fruitlets on flower bud initiation. Bul. Acad. Pol. Sci. Cl. 16: 581-583.

Hester, S.M. and O. Cacho. 2003. Modelling apple orchard systems. Agr. Syst. 77:137-154.

Hoad, G.V. 1984. Hormonal regulation of fruit bud formation in fruit trees. Acta Hort. 149:13-24.

Holiday, D.J. and A. Samal. 1995. Object recognition using L-system fractals. Pattern Recognit. Lett. 16:33-42.

Kittikorn, M., K. Okawa, H. Ohara, N. Kotoda, M. Wada, M. Yokoyama, O. Ifuku, S. Yoshida, and S. Kondo. 2011. Effects of fruit load, shading, application on MdTFL1 and MdFT1 genes in apple buds. Plant Growth Regulat. 64:75-81.

Kittikorn, M., N. Shiraishi, K. Okawa, H. Ohara, M. Yokoyama, O. Ifuku, S. Yoshida, and S. Kondo. 2010. Effect of fruit load on 9,10-ketoloctadecadienoic acid (KODA), GA and jasmonic acid concentrations in apple buds. Sci. Hort. 124:225-230. Yoshihara, and K. Nabeta. 2005. Allenoxidecyclase is essential for theobroxide-induced jasmonic acid biosynthesis in Pharbitis nil. Biochem. Biophys. Res. Commun. 336:1150-1156.

Kucera, B., M.A. Cohn, and G. Leubner-Metzger. 2005. Plant hormone interactions during seed dormancy release and germination. Seed Sci. Res. 15:281-307. and 9,10-ketol-octadecadienoic acid (KODA)

Kong, F., J. Abe, K. Takahashi, H. Matsuura, T.
Luckwill, L.C. 1970. The control of growth and fruitfulness of apple trees, p. 237-253. In: Luckwill, L.C. and C.V. Cutting (eds.). Physiology of tree crops. Academic Press, London, UK, New York, NY.

Mandelbrot, B. 1967. How long is the coast of Britain? Statistical self-similarity and fractal dimension. Science 156:636-638.

Müller, B. and J. Sheen. 2008. Cytokinin and auxin interaction in root stem-cell specification during early embryogenesis. Nature 453:10941097.

Nichols, D., C.G. Embree, and S.A.E. Fillmore. 2011. Dormant spur-wood pruning severity impacts on vegetative growth, blossom intensity and fruit weight of 'Honeycrisp' apple trees. Acta Hort. 903:681-687.

Paradis, E., J. Claude, and K. Strimmer. 2004. APE: Analyses of phylogenetics and evolution in R language. Bioinformatics 20:289-290.

Prusinkiewicz, P. and A. Lindenmayer. 1990. The algorithmic beauty of plants. Springer-Verlag, New York, NY

R Development Core Team. 2011. R: A language and environment for statistical computing. $\mathrm{R}$ Foundation for Statistical Computing, Vienna, Austria. 4 June 2011. <http://www.R-project.org/> .

Ramírez, H., A. Benavides, V. Robledo, R. Alonso, and J. Gómez. 2004a. Gibberellins and cytokinins related to fruit bud initiation in apple. Acta Hort. 636:409-413.

Ramírez, H., J. Torres, A. Benavides, J. Hernández, and V. Robledo. 2004b. Fruit bud initiation in apple cv. Red Delicious linked to gibberellins and cytokinins. Rev. Soc. Quím. Méx. 48:7-10.

Ramírez, H. and G.V. Hoad. 1981. Effects of growth substances on fruit-bud initiation in apple. Acta Hort. 120:131-136.

Samal, A., B. Peterson, and D.J. Holiday. 2002. Recognizing plants using stochastic L-systems. J. Electron. Imaging 11:50-55.

Stover, E., F. Wirth, and T. Robinson. 2001. A method for assessing the relationship between crop load and crop value following fruit thinning. HortScience 36:157-161.

Suzuki, M., S. Yamaguchi, T. Iida, I. Hashimoto, H. Teranishi, M. Mizoguchi, F. Yano, Y. Todoroki, N. Watanabe, and M. Yokoyama. 2003. Endogenous a-ketol linolenic acid levels in short dayinduced cotyledons are closely related to flower induction in Pharbitis nil. Plant Cell Physiol. 44:35-43.

Tromp, J. 2000. Flower-bud formation in pome fruits as affected by fruit thinning. Plant Growth Regulat. 31:27-34.

Vicsek, T. 2001. Fluctuations and scaling in biology. Oxford University Press, New York.

Willaume, M., P.-E. Lauri, and H. Sinoquet. 2004. Light interception in apple trees influenced by canopy architecture manipulation. Trees (Berl.) 18:705-713.

Yokoyama, M., S. Yamaguchi, T. Iida, A. Suda, T. Saeda, T. Miwa, K. Ujihara, and J. Nishio. 2005. Transient accumulation of $\alpha$-ketollinolenic acid (KODA) in immature flower buds of some ornamental plants. Plant Biotechnol. 22: 201-205.

Yokoyama, M., S. Yamaguchi, S. Inomata, K. Komatsu, S. Yoshida, T. Iida, Y. Yokokawa, M. Yamaguchi, S. Kaihara, and A. Takimoto. 2000. Stress-induced factor involved in flower formation of Lemna is an $\alpha$-ketol derivative of linolenic acid. Plant Cell Physiol. 41:110 113.

Zhang, D., A. Samal, and J.R. Brandle. 2007. A method for estimating fractal dimension of tree crows from digital images. Intl. J. Patt. Recog. Art. Intell. 21:561-572. 